Open Access

\title{
Why it is hard to explain Chinese face?-FACE measurement models and its influence on ecological product preference
}

Zhuomin Shi, Zaoying Kuang and Ning Yang

\author{
* Correspondence: \\ mnsszm@mail.sysu.edu.cn \\ Sun Yat-Sen Business School, Sun \\ Yat-Sen University, Guangzhou \\ 510275, China
}

\begin{abstract}
Face in China is a well-known word but still lacks a precise and authoritative definition. Other than the counterpart connotation of social norms in western culture, Chinese face is also a cultural construct strongly connected with situational context. In order to explore the general context and the specific connotation of Chinese face, this paper focuses on comparing the difference between reflective model and formative model when measuring the construct of Chinese face. We find that RM is more reliable and stable than FM in terms of face measurement, but is inferior to FM in explaining the connotations of Chinese face. Moreover, we also explore the effects of different dimensions of Chinese face on consumer preference for ecological products. This study not only enriches the existing research on Chinese face, but also exploratively answers a controversial problem in this area. Furthermore, the findings in this study also provide theoretical support for building an environmentally-friendly society in China.
\end{abstract}

Keywords: Face, Reflective Model (RM), Formative Model (FM), Ecological Product Preference

\section{Introduction}

People often behave similarly to those around them but sometimes also want to be different from others because of the identity signaling effect (Berger and Heath 2007; Chan et al. 2012). This is a worldwide phenomenon emerging not only in the west but in eastern countries such as China as well. However, compared to social identity in the west, people in eastern cultures are more likely to be concerned about face. They care more about others' opinions and the social effects resulting from their own behavior. This kind of social effect manifests as face ( $\mathrm{Li}$ and $\mathrm{Su} 2007$ ). Not only is it something to be gained through human interaction with specific situational characteristics (Ho 1976; Zhou et al. 1993; Hwang, et al. 2002), face also expresses some stable individual characteristics (Chen 1982). So far, even though research on face has attracted numerous scholars, the meaning and dimensions of face remain unsettled, and a universal definition with popular recognition is lacking. Therefore, researchers incline to use their own measurement methods to explain face. For example, Zhang (2012) uses a reflective model (RM), which consists of generalized indicators, while Bao and Zhao (2009) and Shi et al. (2012) use a formative model (FM) constructed from situational 
indicators instead. In fact, both models have advantages and disadvantages in consistency and the interpretation of latent variables with their differences shown through empirical studies (Diamantopoulos and Winklhofer 2001). Scholars in China and abroad have shown more interest in both RM and FM in recent years. Zhou et al. (2007) studied the relationship between suppliers and retailers in Chinese marketing channel which led to a discussion about testing the internal validity and discriminant validity of a formative scale. As well, when exploring the dependence and conflicts in China's marketing channels, Zhou et al. (2007) specified that the measurement of dependence of suppliers on retailers is formative and vice versa. However, few scholars have discussed the utilization of FM and RM with regards to research on face.

In addition to research on measurement tools, research on the effect of face on ecological consumption is also insufficient. The rapid increase of poor air quality in many areas in China has triggered enormous social consciousness. Unprecedentedly, reference to one type of air pollution, PM2.5, was included in the 2012 official government work report. Ecological consumption consequently generated considerable interest from the Chinese government and scholars as a way to address current pollution problems. As a matter of fact, Chinese consumers' consumption is deeply influenced by face culture (Jap 2010). Nevertheless, most existing research concentrates on luxury goods consumption (e.g. Bearden and Etzel 1982; Wong and Ahuvia 1998; Zhang 2012) instead of ecological consumption. Importantly, Shi et al. (2014) preliminarily have shown that the concept of face has strong predictability for ecological consumption as a moderator, while four separate dimensions of face fail to show the same moderating effect. The authors suggest two possible explanations: conceptual reason and methodological reason. The conceptual explanation is mainly rooted in the integrity, coordination, simultaneity and dynamics of face consciousness, indicating that face is a concept that cannot be divided. On the other hand, a methodological explanation notes that at present, no scales and models for measuring face are generally accepted. Thus, if one is seeking to understand the underlying mechanism between face and ecological consumption, an important first step is to locate a more scientific and precise scale.

This paper aims to resolve two problems with research on face. First we examine the advantages and disadvantages of FM and RM. We examine the use of a RM of face in study 1 . Then, in study 2, we run an empirical test to compare RM and FM particularly with regards to stability and validity. By selecting a better measurement scale as a result of study 2, we expect that the connation between face and ecological consumption will be more understandable. Hence, we will investigate the effect of face on ecological product preference in study 3.

\section{Literature review}

\section{Measurement models}

Measurement models are one part of structural equation modeling (SEM), which demonstrates the relationship between indicators and latent variables. Normally, a latent variable is defined and measured by a group of indicators and questions. In short, a change in latent variables leads to a change in indicators (Diamantopoulos and Winklhofer 2001). In 
this case, the indicator is called a reflective indicator or effect indicator and the corresponding measurement model is known as a reflective model (RM). However, Blalock (1964) believed that in certain circumstances, the change to the indicator may be the cause of the change to the latent variable and as a result, formative indicators or causal indicators (MacKenzie et al. 2005) and the corresponding formative model (FM) are formed. Unfortunately, in the existing literature, especially in the field of psychology, most scholars seldom critically consider the relationship between indicators and latent variables, and they usually uncritically adopt RM to conduct research (Jarvis et al. 2003).

As shown in Figs. 1 and 2, factor loadings $\lambda$ shows the relationship between the indicator and latent variables in RM, while weighted coefficient $\gamma$ plays the part in FM.

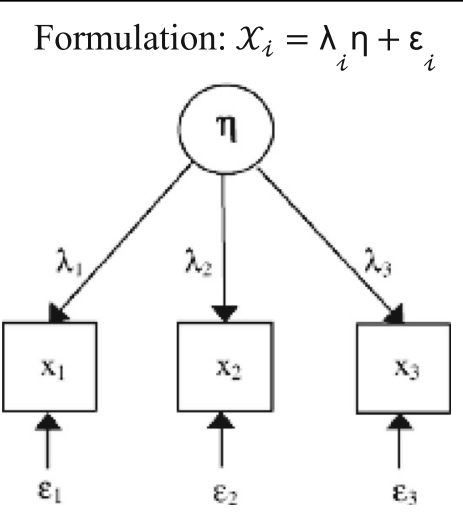

Fig. 1 Reflective Model (RM)

$$
\text { Formulation: } \eta=\mathrm{v}_{1} x_{1}+\mathrm{v}_{2} x_{2}+\cdots+\mathrm{v}_{i} x_{i}+\zeta
$$

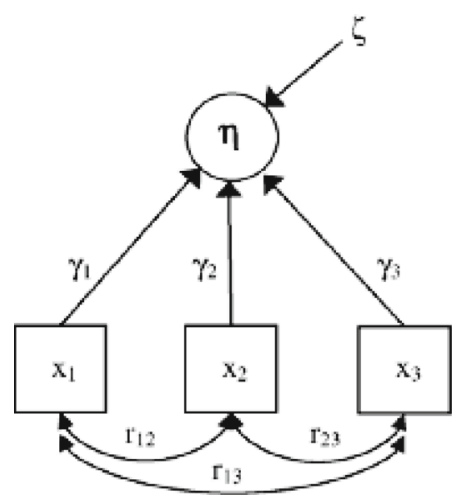

Fig. 2 Formative Model (FM) 
Distinctions between RM and FM include whether measurement indicators influence the latent variables or the other way around, whether all the indicators are interchangeable and their different measurement errors (Diamantopoulos 2006; MacKenzie et al. 2005). However, choosing a measurement model is not an either-or thing. In some cases, either RM or FM is insufficient, whereas the most precise model is the combination of both (Bollen and Lennox 1991). Also, choosing RM or FM is not related to the nature of the variables, and what truly matters is the researcher's own theoretical understanding and definition of the latent variables. Apart from the simplest first-order RM and FM shown in Figs. 1 and 2, Diamantopoulos et al. (2008) discussed a more complicated second-order measurement model. In a second-order model, some latent variables are made of multiple dimensions and every single dimension can be measured by indicators such as a latent variable. Since both indicators and latent variables could be either reflective or formative, four types of measurement models are accordingly generated: (1) first-order formative and second-order formative, (2) first-order reflective and second-order formative, (3) first-order formative and second-order reflective and (4) first-order reflective and second-order reflective.

In addition to the differences in definition, RM and FM vary in empirical analysis, too. For one thing, the processes for reliability analysis are various. Specifically, within RM, there is a completed analytical paradigm, in which internal consistency is indicated by common indicators such as CITC and Cronbach's $\alpha$. However, in FM internal consistency is not applicable because the correlation among measurement indicators could be positive, negative or zero (Diamantopoulos and Winklhofer 2001). In fact, the reliability analysis of FM is controversial. Some think there is no necessity for testing reliability in an FM (Rossiter 2002) while Diamantopoulos (2005) argued that test-retest reliability is advisable. For another, the processes of validity analysis are also different. Specifically, the validity of RM is normally judged by AVE and factor loadings, but in FM, coefficient $\gamma$ (Fig. 2) plays this part. $\gamma$ indicates the effect on latent variables driven by indicators and simultaneously reflects validity (Bollen 1989). If $\gamma$ shows no significance, indicators are invalid and ought to be removed. Nevertheless, Diamantopoulos and Winklhofer (2001) and MacKenzie et al. (2005) introduced an overall generality indicator as a possible way to test validity, arguing that the validity between correlated indicators and overall indicators becomes the final validity for the whole FM. Moreover, model estimation and fitting vary as well. Supposing that FM is analyzed as RM, it will lead to deviation on parameter estimation as well as error on defining latent variables (Jarvis et al. 2003; MacKenzie et al. 2005; Petter et al. 2007), causing a less effective or scientific result.

\section{Research on face}

Face is an essential part of Chinese traditional culture. As Lin (1935) stated in his book "My Country and My People", face is the subtlest standard in Chinese behavioral norms and it impacts Chinese behavior in a profound way. Face includes complicated connotations as well as a variety of meanings. Researchers find it extremely hard to define face precisely, only reaching a consensus that face is a motive for behavior. Goffman 
(1967) proposed that face is gained from others in some specific social interactions, and it refers to a social positive value that others think one should gain, a self-portrait depicted by approved social attributes. Ho (1976) defined face as respect and reverence acquired from others based on decent behaviors in line with one's identity and social status. Obviously, Chinese face is not only a psychological construct (individual image claimed by oneself or approved by the group), but also a social construct (reputation, status and respect authorized by the group). As well, it is a popular belief that face has multiple dimensions. Early in the scholarly discussions on face, $\mathrm{Hu}$ (1944) divided face into LIAN and MIAN. LIAN represents the respect received from the group because of one's morality and MIAN represents social status received from society based on one's success and identity. Following Hu's theory, King and Myers (1977) defined the concepts as "moral face" and "social/status face". Zhu (1987) also thought that face consists of at least personal success and morality, similar to the face duality that includes social and moral face. Through an explorative study, Bao and Zhao (2009) highlighted three dimensions of individual need for face, which are ability-based, relationship-based and morality-based. Among them, morality-based face need refers to individual's expectation of his/her character and morality being recognized by others, initiating from selfconstraint. Instead of originating from inner moral standards, ability-based face need and relationship-based face need are gained from external social groups according with social norms, and include social status, politics power, personal success, strong social networks, etc. Interestingly enough, the morality dimension is in line with the concept of LIAN (Hu, 1944) while the dimensions of ability and relationship are comparable to MIAN. Later, Shi et al. (2012) developed 4 dimensions of face: morality-oriented, ability-oriented, status-oriented and social relationship-oriented, whereby moralityoriented face serves as the only dimension of LIAN, while the other three serve as dimensions of MIAN. In this paper, we adopt a definition of face that is constructed by LIAN (moral face) and MIAN (social face) (Shi et al. 2012). In other words, face itself is a second-order formative model.

Nonetheless, this article emphasizes a first-order measurement model and measurement indicators of those four dimensions. Even renowned Chinese writers have difficulty in providing a precise explanation of face, thinking it abstract and untouchable (Lin 1935). In addition, it contains both situational (Ho 1976; Zhou 1993; Hwang 2002) and chronic (Chen 1982) characteristics. Hence, some scholars put situational indicators into use, building the FM of face (Bao and Zhao 2009; Shi 2012). For example, indicators like "able to achieve something that others are unable to", "betray and sell out your friends" and "not bring enough money when treating others" are situational indicators causing one to have/lose face. They designate the cause of face, and are logically reckoned as causal indicators in FM, manifesting different dimensions of face. However, other scholars utilize RM to test the concept of face through general indicators which serve as consequences owing to face, such as "I long to possess something people desire to own but do not" and "I hope in others' eyes, I have a better life than the majority". Those indicators are the effect of valuing face seriously, thus recognized as effect indicators in RM. When studying face empirically, most researchers first choose RM because of its strong stability. Yet there is no scientific evidence to prove whether RM is superior to FM. Therefore, this paper conducts an empirical analysis, presenting the distinctions between RM and FM on stability and validity in 
terms of capturing face. We summarize the scales of FM and RM in academic research (Table 1).

This article adopts the scales developed by Chan et al. (2009) and Zhang et al. (2012) as they are more recent and simplified with at most 11 items. In addition, $\mathrm{Li}$ and $\mathrm{Su}$ (2007) developed 9 explorative measurement items for how face influences consumption. $\mathrm{Li}$ and $\mathrm{Su}$ (2007) connected face and consumption behavior that matches the definition of a reflective indicator. Therefore, $\mathrm{Li}$ and Su's measurement items are taken into account, too. As well, for accuracy, another in-depth interview is conducted to deepen the development of RM for measuring the concept of face. As for FM, since Shi et al. (2012) expanded the study of face measurement on the basis of Bao and Zhao's (2009) work, we follow Shi et al. (2012) directly. To conclude, our research fully uses the scale of Shi et al. (2012) for FM and the scales of Zhang (2012), Chan et al. (2009), and $\mathrm{Li}$ and $\mathrm{Su}$ (2007) as part of the measures of RM.

Study of the influence of face mechanisms on consumer behavior include two streams, exploring face as a whole concept or in separate dimensions. As a whole, face influences quite a number of consumer behaviors, such as conspicuous consumption (Zhang 2012), luxury consumption and exclusive consumption, gift giving, etc. Chinese consumers purchase products because of the need of face in most situations (Jap 2010) and the need for social approval in social interactions (Chen 1982). It can be easily deduced that consumers with strong face consciousness are more concerned about extrinsic attributes of a product (brand, reputation and price) rather than intrinsic attributes (function and quality), so that they can gain face or avoid losing face (Belk 1988). Face helps promote consumers' brand awareness so that price sensitivity may be lowered. Beyond that, face has an impact on the personal understanding of luxury ads (Shi et al. 2012). As well, separating face into LIAN and MIAN, scholars have further studied the effect of these two dimensions on consumer behavior. Analyzing the difference and sameness between LIAN and MIAN, Zhai (1995) built the model of Chinese face consciousness at the same time. Taking this one step further, Shi et al. (2011) proved a significant difference between LIAN and MIAN through grounded theory, which reflects distinctive psychological cognition across diverse product categories. Moreover, Shi et al. (2011) found that consumers who have high MIAN consciousness have a predilection for brands from developed countries. They pursue famous brands, high prices and fashionable design. Namely, they hold much more explicitly positive attitudes

Table 1 Summary of measurement scales on face

\begin{tabular}{|c|c|c|c|}
\hline Scholars (year) & $\begin{array}{l}\text { Genre of measurement } \\
\text { scale }\end{array}$ & $\begin{array}{l}\text { Item } \\
\text { number }\end{array}$ & Dimensions \\
\hline Chen (1982) & $\mathrm{RM}$ & 40 & $\begin{array}{l}\text { Love face (i.e. concerned about face a lot), Thin } \\
\text { face (i.e. easy to feel ashamed when losing face) }\end{array}$ \\
\hline Chou (1996) & $\mathrm{RM}$ & 50 & $\begin{array}{l}\text { Protective face orientation, Acquisitive face } \\
\text { orientation }\end{array}$ \\
\hline Chan et al. (2009) & $\mathrm{RM}$ & 8 & Concern for face \\
\hline Bao and Zhao (2009) & FM & 35 & $\begin{array}{l}\text { Ability-based face need, Relationship-based } \\
\text { face need and Morality-based face need }\end{array}$ \\
\hline Shi et al. (2012) & FM & 22 & $\begin{array}{l}\text { Morality-oriented face, Ability-oriented } \\
\text { face, Status-oriented face and Social } \\
\text { relationship-oriented face }\end{array}$ \\
\hline Zhang et al. (2012) & RM & 11 & Desire to gain face, Fear of losing face \\
\hline
\end{tabular}


towards foreign brands over domestic ones. However, Chinese consumers consider purchasing Japanese cars as "gaining MIAN but losing LIAN". Incongruent with patriotism, buying Japanese goods violates national morality. As a result, compared to Japanese brands, consumers hold implicit positive attitudes to Chinese brands. It also demonstrates that instead of LIAN (moral face), MIAN (social face) is the reason for the desire to chase after status goods and luxury goods (Bearden and Etzel 1982; Wong and Ahuvia 1998), and importantly, again it shows that face is a multidimensional construct.

Above all, there is no universal definition or a recognized measurement scale of face since it is complicated. As a result, scholars use both FM and RM to measure face. Even though no evidence can prove that RM is better than FM, scholars tend to choose RM owing to its strong stability. In terms of the influence of face on consumption behavior, current studies are mainly divided into two streams, viewing face as a whole construct or a multi-dimension construct. Furthermore, most are connected to luxury good consumption while ecological consumption is ignored.

\section{Study 1: A Re-exploration of a reflective model of face}

The purpose of study 1 is to re-explore reflective measurement scales, achieve a reflective model (RM) of face through explorative factors analysis, and conduct confirmatory factor analysis to lay the foundation for study 2 .

\section{Questionnaire design}

First, based on the existing reflective measurement scales of face (Zhang 2012; Chan et al. 2009; Li and Su 2007), combining some modifications, we initially reorganized 12 questions. Next, for accuracy, we held individual in-depth interviews about these 12 questions respectively with $21 \mathrm{MBA}$ students. After discussion within the research group summarizing the questions that addressed similar meanings, we developed 13 new questions. Integrating these two steps, 25 questions were eventually established, and each index mark is shown in Table 2.

\section{Exploratory analysis}

This study uses a convenience sampling survey. Hard-copy questionnaires were distributed to two MBA classes at a university in Guangzhou. 121 questionnaires were distributed, and 114 were collected with 110 valid copies. The collection rate and effective rate are 94.2 and $96.5 \%$ respectively.

\section{Reliability analysis}

In general, the value of the Corrected Item-Total Correlation (CITC) coefficient of a reliable indicator should be more than 0.3. Thus, indicators that could not meet this standard were omitted and that tempered the overall Cronbach's $\alpha$ value. Accordingly, GF22, GF18 and GF12 were removed, with 22 indicators remaining; overall Cronbach's $\alpha$ value was raised from 0.907 to 0.910 . After the first revision, the scale showed a good internal consistency. 
Table 2 Measure indicators combined with previous findings and in-depth interviews

\begin{tabular}{|c|c|c|}
\hline Indicators & Detail description & Source \\
\hline GF1 & I hope that I can solve problems others cannot. & \multirow[t]{6}{*}{ Zhang (2012) } \\
\hline GF2 & I long to possess something people desire to own but do not. & \\
\hline GF3 & I want others to think well of me. & \\
\hline GF4 & I hope I can let others know I have some friends with high status. & \\
\hline GF5 & I hope in others' eyes, I have a better life than the majority. & \\
\hline GF6 & I will try my best to conceal my drawbacks in front of others. ${ }^{b}$ & \\
\hline GF7 & I am concerned about others' attitudes towards me. & \multirow[t]{4}{*}{ Chan et al. (2009) } \\
\hline GF8 & I am concerned about others' criticism towards me. & \\
\hline GF9 & I am concerned about others' looking down upon on me. & \\
\hline GF10 & My identity and social status are essential to myself. & \\
\hline GF11 & What I consume should correspond to my identity and social status. ${ }^{b}$ & \multirow[t]{2}{*}{ Li and Su (2007) } \\
\hline GF12 & $\begin{array}{l}\text { When buying a gift for someone, I am usually concerned about the } \\
\text { prestige of the gift. }\end{array}$ & \\
\hline GF13 & I hope in others' opinion, I perform better than the majority. ${ }^{b}$ & \multirow{13}{*}{$\begin{array}{l}\text { Organized by in-depth } \\
\text { interviews }\end{array}$} \\
\hline GF14 & I hope compared with others' possessions, I own something of higher class. & \\
\hline GF15 & $\begin{array}{l}\text { I think no matter how hard it is, one should maintain the same } \\
\text { consumption level as others. }\end{array}$ & \\
\hline GF16 & I hope I know a lot of people. & \\
\hline GF17 & I hope I have friends with high status. & \\
\hline GF18 & I hope my friends will give me a hand unhesitatingly when I have trouble. ${ }^{a}$ & \\
\hline GF19 & $\begin{array}{l}\text { I hope I can have good conversation and interaction with others during } \\
\text { social activities. }\end{array}$ & \\
\hline GF20 & I hope I can behave well. & \\
\hline GF21 & I hope I can become a model others look up to. & \\
\hline GF22 & I pay attention to my performance in public. ${ }^{a}$ & \\
\hline GF23 & I am concerned about whether what I do accords with my identity. & \\
\hline GF24 & I am concerned about whether my behavior meets the social norms. & \\
\hline GF25 & If I do something indecent, I will feel embarrassed. & \\
\hline
\end{tabular}

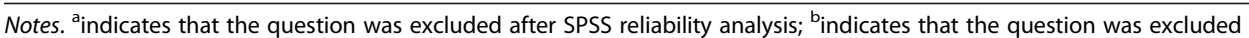
after LISREL exploratory analysis

\section{Principal component analysis}

Kaiser-Meyer-Olkin measure of sampling adequacy and Bartlett's Test of Sphericity were run in SPSS17.0, in order to determine whether the data proved suitable for factor analysis. The results showed that the KMO is 0.835 , greater than 0.7 , and Bartlett's Test of Sphericity was significant at the 0.01 level. Hence, the sample data was suited for factor analysis. Then, the LISREL analysis was used for principal component analysis, and 10 principal components were assumed at the beginning. According to the results, the total explained variance for the first four factors was $62.57 \%$, over $60 \%$. Since in this study, the FM of face is constructed on the measurement model of four dimensions created by Shi et al. (2012), we followed the structure of the four factors for the exploration of RM of face for better comparison.

\section{Exploratory factor analysis}

Through the LISREL analysis, we calculated the varimax-rotated factor loadings. Next, indicators were removed in the following circumstances: 1 ) factor loadings of which are less than 0.4 ; 2) simultaneously landing on multiple factors; 3 ) not falling on any factor. 
Accordingly, after deleting GF6, GF10, GF11, GF13 and GF15, 17 measurement indicators were reserved. Then, we ran an exploratory factor analysis again, with a KMO outcome of 0.827 . Bartlett's Test of Sphericity remained significant at 0.01 . The reliability analysis and exploratory factor analysis results are shown in Table 3, which obviously demonstrates that the second revision is better with a higher internal consistency of the scale.

According to the analysis results, the RM measurement scale for face was supported. In factor 1, all four indicators described personal concerns about others' attitudes and compliments towards oneself, associated with individual identity and social status. Therefore, we named this group status-oriented face. In factor 2, four indicators showed one's relationship with others, named social relationship-oriented face. Within factor 3, four indicators were related to personal capability, such as having a better life, so this group was named ability-oriented face. Finally, the five indicators of factor 4 were related to personal morality, and were named morality-oriented face. Statusoriented face, social relationship-oriented face and ability-oriented face are three constituent dimensions of MIAN, while morality-oriented face is the only component of LIAN, consistent with the findings of Shi et al. (2012).

\section{Confirmatory factor analysis}

MBA students and a small portion of undergraduates at a university in Guangzhou participated in the convenience sampling survey. 260 surveys were handed out with 247 questionnaires returned, a collection rate of 95\%. A questionnaire with 10 answers that were the same in a row was invalidated. After excluding invalid questionnaires, 236 valid ones were retained, with an effective rate of $95.5 \%$. In order to facilitate follow-up

Table 317 measurement indicators of exploratory factor analysis

\begin{tabular}{llcllll}
\hline Factors & Indicators & Factor loadings & CITC & Cronbach's a & Eigenvalues & Interpretable variance \\
\hline Factor 1 & GF3 & 0.76 & 0.871 & 0.898 & 7.88 & $35.84 \%$ \\
& GF7 & 0.82 & 0.860 & & & \\
& GF8 & 0.82 & 0.859 & & & \\
& GF9 & 0.72 & 0.882 & & 2.55 & $11.60 \%$ \\
Factor 2 & GF4 & 0.71 & 0.733 & 0.792 & & \\
& GF16 & 0.62 & 0.741 & & & \\
& GF17 & 0.87 & 0.648 & & & \\
& GF19 & 0.53 & 0.807 & & 1.83 & \\
& GF1 & 0.52 & 0.840 & 0.827 & & \\
& GF2 & 0.81 & 0.731 & & & \\
& GF5 & 0.62 & 0.817 & & & \\
& GF14 & 0.80 & 0.722 & & & \\
Factor 4 & GF20 & 0.53 & 0.789 & 0.799 & & \\
& GF21 & 0.52 & 0.790 & & & \\
& GF23 & 0.74 & 0.737 & & & \\
& GF24 & 0.75 & 0.734 & & & \\
& GF25 & 0.71 & 0.745 & & & \\
\hline
\end{tabular}


research, 17 measurement indicators were re-labeled. In addition, in front of every indicator, "RM" was put so as to distinguish the measurement indicators from FM.

SPSS 17.0 and LISREL software were used to test the reliability and validity of the RM of face (Table 4). It was apparent that the CITC corresponding to every factor was greater than 0.5 , and all the Cronbach's $\alpha$ values were greater than 0.7 , which indicates the scale has good reliability. Furthermore, $\chi^{2} / d f=2.44<3$, CFI $=0.94, \quad$ IFI $=0.94$, $\mathrm{NFI}=0.90$, NNFI $=0.92$, RMSEA $=0.068<0.08$. As well, the standardized basic factor loadings were greater than 0.5 . All coefficients were entirely within the acceptable range. Accordingly, the data had excellent fit.

Then, we calculated the value of an average variance extracted (AVE) and composite reliability (CR) of four factors (Table 5). We can see that the RM of face has good convergent validity and discriminant validity. Accordingly, the RM of face in study 1 has good reliability and validity, which is scientifically acceptable.

\section{Study 2: Comparative analysis of two measurement models} Analytical methods and indicators

Via exploratory analysis and confirmatory analysis, study 1 supports the use of RM for measuring face. The purpose of study 2 is to look into the differences between the two models, particularly with regards to the models' stability and the ability to interpret the concept of face. We introduce the FM of face built on Shi et al.'s (2012) work.

With regards to a data analytical method, currently partial least squares regression (PLS) is relatively more recognized by scholars (Fornell and Bookstein 1982; Coltman et al. 2008). Unlike covariance matrix analysis, PLS analysis does not require the data to present normal distribution, so even with a small sample size, PLS is practical

Table 4 Reliability and validity analysis results for the RM of face

\begin{tabular}{|c|c|c|c|c|c|c|c|}
\hline $\begin{array}{l}\text { Latent } \\
\text { variable }\end{array}$ & Dimensions & Indicators & $\begin{array}{l}\text { Factor } \\
\text { loadings }\end{array}$ & CITC & $\begin{array}{l}\text { Composite } \\
\text { reliability }\end{array}$ & Cronbach's a & $\begin{array}{l}\text { Overall } \\
\text { Cronbach's a }\end{array}$ \\
\hline \multirow[t]{17}{*}{ Face } & \multirow[t]{5}{*}{ Morality-oriented face } & RMF1 & 0.85 & 0.773 & \multirow[t]{5}{*}{0.875} & \multirow[t]{5}{*}{0.873} & \multirow[t]{17}{*}{0.899} \\
\hline & & RMF2 & 0.81 & 0.704 & & & \\
\hline & & RMF3 & 0.79 & 0.734 & & & \\
\hline & & RMF4 & 0.64 & 0.615 & & & \\
\hline & & RMF5 & 0.72 & 0.686 & & & \\
\hline & \multirow[t]{4}{*}{ Ability-oriented face } & RMF6 & 0.70 & 0.662 & \multirow[t]{4}{*}{0.873} & \multirow[t]{4}{*}{0.871} & \\
\hline & & RMF7 & 0.74 & 0.711 & & & \\
\hline & & RMF8 & 0.91 & 0.812 & & & \\
\hline & & RMF9 & 0.82 & 0.720 & & & \\
\hline & \multirow[t]{4}{*}{ Status-oriented face } & RMF10 & 0.91 & 0.840 & \multirow[t]{4}{*}{0.9114} & \multirow[t]{4}{*}{0.910} & \\
\hline & & RMF11 & 0.88 & 0.819 & & & \\
\hline & & RMF12 & 0.82 & 0.787 & & & \\
\hline & & RMF13 & 0.78 & 0.746 & & & \\
\hline & \multirow{4}{*}{$\begin{array}{l}\text { Social Relationship-oriented } \\
\text { face }\end{array}$} & RMF14 & 0.77 & 0.722 & \multirow[t]{4}{*}{0.899} & \multirow[t]{4}{*}{0.898} & \\
\hline & & RMF15 & 0.88 & 0.816 & & & \\
\hline & & RMF16 & 0.83 & 0.769 & & & \\
\hline & & RMF17 & 0.84 & 0.790 & & & \\
\hline
\end{tabular}


Table 5 AVE and CR of the RM of Face

\begin{tabular}{lllll}
\hline & $\begin{array}{l}\text { Morality-oriented } \\
\text { face }\end{array}$ & $\begin{array}{l}\text { Ability-oriented } \\
\text { face }\end{array}$ & $\begin{array}{l}\text { Status-oriented } \\
\text { face }\end{array}$ & $\begin{array}{l}\text { Social relationship-oriented } \\
\text { face }\end{array}$ \\
\hline Morality-oriented face & 0.7656 & & & \\
Ability-oriented face & $0.312^{\mathrm{a}}$ & 0.7966 & & \\
Status-oriented face & $0.306^{\mathrm{a}}$ & $0.463^{\mathrm{a}}$ & 0.8490 & \\
Social relationship-oriented & $0.309^{\mathrm{a}}$ & $0.414^{\mathrm{a}}$ & $0.403^{\mathrm{a}}$ & 0.8310 \\
face & & 0.6345 & 0.7208 & 0.6905 \\
AVE & 0.5861 & 0.6345 & \\
\hline
\end{tabular}

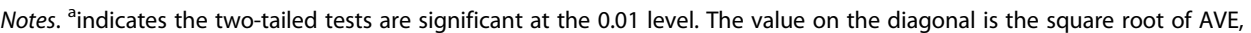
and below the diagonal is correlation coefficient value between latent variables

(Fornell and Bookstein 1982; Gudergan et al. 2008; Baxter 2009). Also, it can be carried out in the presence of independent variable regression modeling where there is multicollinearity. Therefore, it is easier to explain the regression coefficients in each variable (Anderson and Gerbin 1988) and to avoid potential issues such as factor indeterminacy or the model not being recognized (Fornell and Bookstein 1982). Generally, common PLS analysis software includes LV-PLS, PLS-Graph, Smart-PLS, etc. We used Smart-PLS software for this study. Previous research on the fitness of statistical indicators for FM is integrated and summarized in Table 6 (Chin 1998; Diamantopoulos and Winklhofer 2001; Jarvis et al. 2003; MacKenzie et al. 2005).

To promote the rigor of comparison, both RM and FM were analyzed using PLS. As well, following Diamantopoulos and Winklhofer (2001) and MacKenzie et al. (2005), we brought in six generalized measurement indicators for the overall concept and dimensions of face. According to Table 6 , stability is determined by factor loadings $\lambda$ or weighted coefficient $\gamma$, and a statistically significant $T$ value, while the validity is evaluated by the correlation coefficient between the latent variables and $\mathrm{R}^{2}$.

\section{Questionnaire design}

We kept the basic FM of face congruent with Shi et al.'s (2012) framework. However, we added six more generalized measurement indicators. Two of them are general indicators of overall face ("In daily life, I care about my own face" and "Overall, I think I care about face a lot"), and four are generalized indicators corresponding to four

Table 6 Indicators for judging the goodness of fit for FM

\begin{tabular}{|c|c|c|}
\hline Category & Content & Judgments \\
\hline \multirow[t]{4}{*}{ Statistically Significant Index } & $\begin{array}{l}\text {-Significance of latent variable index } \\
\text { weighted coefficient } \gamma\end{array}$ & $\begin{array}{l}-T \text { value is significant, and the absolute } \\
\text { value is greater than } 1.96\end{array}$ \\
\hline & $\begin{array}{l}\text {-Significance of latent variable } \\
\text { path coefficients }\end{array}$ & $\begin{array}{l}-T \text { value is significant, and the absolute } \\
\text { value is greater than } 1.96\end{array}$ \\
\hline & -Chi-square significance & -should not be significant \\
\hline & $-G F I$ & -ideal value is greater than 0.9 \\
\hline \multirow[t]{3}{*}{ Statistical Validity Index } & $\begin{array}{l}\text {-latent variable index weighted } \\
\text { coefficient } \gamma\end{array}$ & $\begin{array}{l}\text {-generally greater than } 0.6 \text {, preferably } \\
\text { greater than } 0.7\end{array}$ \\
\hline & $\begin{array}{l}\text {-latent variables standardized } \\
\text { path coefficient }\end{array}$ & $\begin{array}{l}\text {-generally greater than } 0.2 \text {, preferably } \\
\text { greater than } 0.3\end{array}$ \\
\hline & $\begin{array}{l}\text {-regression coefficient of } \\
\text { determination }\left(R^{2}\right)\end{array}$ & -generally greater than 0.2 \\
\hline
\end{tabular}


dimensions ("When I am questioned on my conduct by others, I feel I have no face" and so on). Questionnaires used a 7-point Likert scale. The indicators were labeled to make analysis easier. For example, "FM" was added ahead of every single indicator for FM to increase distinguishability. Two newly incremental overall indicators were labeled as ALLF1 and ALLF2, as well as four indicators labeled AMF1, AAF1 and ASF1, ARF1 (Table 7). The questionnaire for study 2 was distributed along with the questionnaire from study 1 . Thus, the procedure for data collection is exactly the same and in total 236 valid questionnaires were retrieved as reported for study 1 .

\section{Comparative analysis results}

First, using Smart-PLS analysis, we obtained factor loadings $\lambda$ (RM), weighted coefficient $\gamma$ (FM) and significance (T value) of every measurement indicator and latent variables, as well as the CR and AVE of latent variables (Table 8). To ensure a clear comparison, as both models include the same 4 dimensions, we replaced the indicator labels from FMF (Table 7) and RMF (Table 4) with MF, AF, SF and RF (Table 8), representing morality-oriented face, ability-oriented face, status-oriented face and social relationship-oriented face. It is apparent that factor loadings in the RM of face are greater than 0.7 , and significant at the 0.01 level.

Table $\mathbf{7}$ Indicators for the FM of face and incremental generalized measurement indicators

\begin{tabular}{|c|c|c|}
\hline Dimensions & Indicators & Description \\
\hline \multirow[t]{6}{*}{ Morality-oriented face } & FMF1 & I behave indecently in public. \\
\hline & FMF2 & I was told that I am immoral. \\
\hline & FMF3 & I have uncivilized behavior. \\
\hline & FMF4 & Bad habits are known by others. \\
\hline & FMF5 & I quarrel with others in public. \\
\hline & FMF6 & I have no shame, doing something low and cheap. \\
\hline \multirow[t]{4}{*}{ Ability-oriented face } & FMF7 & Compared with my peers, I lead a worse life. \\
\hline & FMF8 & My child or I am not able to enter a university. \\
\hline & FMF9 & I am bad at learning/working. \\
\hline & FMF10 & Friends are talking about a topic that I know nothing about. \\
\hline \multirow[t]{4}{*}{ Status-oriented face } & FMF11 & I work in a small company. \\
\hline & FMF12 & My income is low. \\
\hline & FMF13 & My housing conditions are poor. \\
\hline & FMF14 & I always take a crowded bus to work. \\
\hline \multirow[t]{3}{*}{ Social relationship-oriented face } & FMF15 & People openly criticize me. \\
\hline & FMF16 & I get refused when turning to people for help. \\
\hline & FMF17 & I don't bring enough money when treating others to a meal. \\
\hline \multirow[t]{6}{*}{ Generalized measurement indicators } & ALLF1 & In daily life, I care about my own face. \\
\hline & AMF1 & $\begin{array}{l}\text { When my conduct is questioned by others, I feel } \\
\text { I have no face. }\end{array}$ \\
\hline & AAF1 & When I am not as capable as others, I feel I have no face. \\
\hline & ASF1 & $\begin{array}{l}\text { When I do not have the same social status as others, } \\
\text { I feel no face. }\end{array}$ \\
\hline & ARF1 & $\begin{array}{l}\text { When I am embarrassed in social interactions with others, } \\
\text { I feel I have no face. }\end{array}$ \\
\hline & ALLF2 & Generally, I think I care about face a lot. \\
\hline
\end{tabular}


Table 8 Comparison of the Results of Smart-PLS

\begin{tabular}{|c|c|c|c|c|c|}
\hline \multirow[t]{2}{*}{ Dimensions } & \multirow{2}{*}{$\begin{array}{l}\text { Measurement } \\
\text { indicator }\end{array}$} & \multicolumn{2}{|c|}{ Reflective model (RM) } & \multicolumn{2}{|l|}{ Formative model (FM) } \\
\hline & & $\overline{\text { Factor loadings } \lambda}$ & $\overline{T \text { T value }}$ & Weighted coefficient $\gamma$ & $T$ value \\
\hline \multirow[t]{8}{*}{ Morality-oriented face } & MF1 & 0.7955 & 8.3149 & -0.0689 & 0.5655 \\
\hline & MF2 & 0.7196 & 5.9639 & 0.6438 & 4.6195 \\
\hline & MF3 & 0.7822 & 8.0402 & 0.2782 & 2.0404 \\
\hline & MF4 & 0.8249 & 11.3884 & 0.0710 & 0.7318 \\
\hline & MF5 & 0.8786 & 12.9011 & 0.0858 & 0.8057 \\
\hline & MF6 & & & 0.2346 & 2.0409 \\
\hline & $C R$ & 0.8997 & & & \\
\hline & AVE & 0.6430 & & & \\
\hline \multirow[t]{6}{*}{ Ability-oriented face } & AF1 & 0.7844 & 15.6330 & 0.2490 & 2.0040 \\
\hline & AF2 & 0.8308 & 22.5111 & 0.2170 & 1.3950 \\
\hline & AF3 & 0.9029 & 40.1336 & 0.2442 & 1.8698 \\
\hline & AF4 & 0.8720 & 22.8262 & 0.5043 & 4.3079 \\
\hline & $C R$ & 0.9113 & & & \\
\hline & AVE & 0.7203 & & & \\
\hline \multirow[t]{6}{*}{ Status-oriented face } & SF1 & 0.9217 & 66.0711 & 0.3830 & 2.2965 \\
\hline & SF2 & 0.9070 & 51.0724 & 0.0636 & 0.3246 \\
\hline & SF3 & 0.8594 & 25.0973 & 0.5008 & 2.6671 \\
\hline & SF4 & 0.8626 & 36.8282 & 0.1756 & 1.2490 \\
\hline & $C R$ & 0.9372 & & & \\
\hline & AVE & 0.7887 & & & \\
\hline \multirow[t]{6}{*}{ Social relationship-oriented face } & RF1 & 0.8569 & 38.7145 & 0.5015 & 3.8842 \\
\hline & RF2 & 0.8992 & 50.7292 & 0.3942 & 3.5771 \\
\hline & RF3 & 0.8699 & 36.4603 & 0.3466 & 2.9411 \\
\hline & RF4 & 0.8746 & 41.5258 & & \\
\hline & $C R$ & 0.9291 & & & \\
\hline & AVE & 0.7661 & & & \\
\hline
\end{tabular}

However, in FM, some weighted coefficients $\gamma$ s were insignificant, and many of them are only marginally significant. Thus, the stability of RM is superior to FM in measuring face.

The following step was to calculate the correlation coefficients, $T$ values and the regression coefficient of determination $\mathrm{R}^{2}$ between groups of: 1) four groups of indicators (AMF0, AAF0, ASF0 and ARF0) and increased four generalized indicators (AMF1, AAF1, ASF1 and ARF1); and, 2) four generalized indicators and overall face indicators (ALLF). Wherein, to simplify, AMF0 represents the combination of all MF indicators in either one of the measurement models. Likewise, AAF0, ASF0 and ARF0 stand for AF, SF, RF indicators respectively. Besides, ALLF is the combination of ALLF1 and ALLF2. Table 9 shows that the correlation coefficients in both groups are significant. Nonetheless, the comparison shows that the correlation coefficients in FM are greater than the corresponding ones in RM, and that $\mathrm{R}^{2}$ is the same, higher in FM than in RM. That is, with regards to the ability to interpret generalized indicators in all dimensions, FM is the better choice. Compared to RM, FM can provide a better picture of the construct of face. In addition, a significant positive correlation is found between the overall and four generalized indicators. 
Table 9 Correlation coefficients, $T$ values and $R^{2}$ of the four dimensions and overall concept of face

\begin{tabular}{|c|c|c|c|c|c|c|}
\hline \multirow[t]{2}{*}{ Path } & \multicolumn{3}{|l|}{ Reflective model (RM) } & \multicolumn{3}{|l|}{ Formative model (FM) } \\
\hline & Correlation coefficient & T value & $R^{2}$ & Correlation coefficient & T value & $R^{2}$ \\
\hline AMF0->AMF1 & 0.2148 & 3.6167 & 0.0461 & 0.6067 & 13.8279 & 0.3680 \\
\hline $\mathrm{AAF} 0->\mathrm{AAF} 1$ & 0.2950 & 4.8311 & 0.0870 & 0.5683 & 11.2012 & 0.3230 \\
\hline ASFO->ASF1 & 0.3694 & 6.4111 & 0.1365 & 0.6035 & 14.1563 & 0.3642 \\
\hline ARFO->ARF1 & 0.3244 & 4.6899 & 0.1052 & 0.5901 & 11.9363 & 0.3482 \\
\hline Path & Correlation Coefficient & & T value & & $R^{2}$ & \\
\hline AMF1—>ALLF & 0.1409 & & 2.0057 & & 0.346 & \\
\hline AAF1 $->$ ALLF & 0.2310 & & 2.4341 & & & \\
\hline ASF1->ALLF & 0.3033 & & 3.3470 & & & \\
\hline ARF1— $>$ ALLF & 0.2831 & & 3.3180 & & & \\
\hline
\end{tabular}

Overall, both RM and FM have their own advantages and disadvantages. FM offers a better interpretation of face, while RM has relatively high stability. RM is also superior with significant correlation coefficients between latent variables constructed of measurement indicators and four generalized indicators. To sum up, RM is better at measuring face compared to FM.

In addition, there is a significant positive correlation between the overall and four generalized indicators, and $R^{2}$, the explained variance reaches $34.6 \%$ (Table 9). With the data of the four generalized indicators completely collected, study 3 was developed to explore the influence of the diverse dimensions of face on ecological product preference.

\section{Study 3: Effect of different dimensions of face on ecological product preference}

In study 1 and study 2, we examined the differences between RM and FM, compared how well both models can describe the concept of Chinese face and also showed that face is composed of 4 dimensions. However, we have yet to show the link between face and consumption behavior. The purpose of study 3 was to test various effects of the different dimensions of Chinese face on preferences for the consumption of ecological products.

Since October 2011, the Chinese public has become more and more aware that haze, and in particular, of the serious health impacts of small particulate matter (PM 2.5) which is small enough to pass through alveoli into the bloodstream. One of the sources of PM2.5 in everyday life is the vehicle exhaust emissions. The government and environmentalists in China have been promoting green transportation as one way to improve air quality, especially new energy passenger vehicles in light that over $27 \%$ new cars sold in 2015 all over the globe run on Chinese roads, according to the International Organization of Motor Vehicle Manufacturers. Therefore, we chose environmentally friendly cars as our study object.

Prosocial behavior, such as ecological product consumption, enables consumers to express social responsibility and personal concern for the environment (Connolly and Prothero 2003), thereby improving the evaluation for their own reputation (Milinski et al. 2002). Face drives people to care about their image and how others evaluate them, 
so it may strongly affect ecological consumer behavior (Shi et al. 2014). However, there has been limited empirical research conducted on the impact of face on ecological consumer behavior, especially in terms of the cognitive differences between LIAN and MIAN, as most research has examined face as a whole concept associated with luxury goods consumption. Thus, exploring whether the different dimensions of face impact ecological product preference will aid us in understanding the mechanisms of face better.

\section{Research hypothesis}

Intrinsic, extrinsic and image/reputation are three types of consumer prosocial behavior motivations (Bénabouand and Tirole 2006). Image motivation originates from consumer impression management, which guides individuals to present prosocial and moral behavior, so as to leave a positive impression on others (Griskevicius et al. 2010). Moreover, if individuals engage in prosocial behavior, they gain both a prosocial reputation and others' praise, a symbol of personal virtue (Griskevicius et al. 2010; Delmas and Lessem 2014). Logically, when consumers proactively implement environmentally friendly behavior and embody the spirit of self-sacrifice, they will be certain to reap others' respect, appreciation and recognition. In addition, Peloza et al. (2013) combined the study of self-standard compliance and self-discrepancy theory, proposing that the morality of sustainable behavior is an important self-standard. However, in reality, actual behavior is not always in line with this standard. Therefore, when consumers have a strong sense of self-responsibility, they desire to meet their own internal ethical standards by choosing moral or environmental products. Thus, either for building a good reputation or for meeting inner moral requirements, consumers would choose ecological or ethical products rather than non-ecological ones.

Face can be split into LIAN and MIAN (Hu 1944; King and Myers 1977; Bao and Zhao 2009). MIAN represents social status won by extrinsic achievement, while LIAN stands for image and reputation gained from obeying moral standards (Zhu 1987; Bao and Zhao 2009). For the sake of gaining and maintaining one's face, it is easy for consumers to buy high priced products, attached to a conspicuous brand identity, manufactured by developed countries (Shi et al. 2011) and that are unique (Chan et al. 2009). Furthermore, rather than LIAN, MIAN provides the motivation for the craze about status goods and western luxury goods (Wong and Ahuvia 1998; Wong and Zaichkowsky 1999; Tse, 1996). Namely, MIAN is social-oriented and leads to concern about social status and financial strength, while LIAN is morality-oriented, and propels prosocial behavior. To put it formally, we present hypotheses H1a and H1b:

H1a. Compared with social-oriented face (MIAN), consumers with stronger morality-oriented face (LIAN) have a greater preference for ecological products.

H1b. Compared with morality-oriented face (LIAN), consumers with stronger socialoriented face (MIAN) have a greater preference for non-ecological luxury products.

\section{Sample analysis}

Data for study 3 was collected along with the data for study 2 as well as study 1 (confirmatory analysis). Before answering the survey questions, participants were required to read the following manipulated purchase scenario. Predilection was measured on a 7-point scale and was worded, "If these two cars are of the same price and within your 
affordable range, which car would you prefer?", with endpoints "car A/car B". The specific situation was set as follows:

Suppose that you are now ready to buy a car, and you find after research, there are two cars with the same market price. The following is the detailed description of two vehicles: A car is a product of a well-known brand. The car brand has always been an emblem of identity and status, world-renowned for its luxury, and it has become the first choice for the successful;

B car is an environmentally friendly car of some brand. It can effectively reduce fuel consumption and exhaust emissions, favorable to the environment, and it has become the first choice for environmentalists.

For better determining whether the participants are of the target group we expect, we studied their demographic characteristics as follow. 129 males and 107 females participated, mainly middle aged and youth (born from 1974 to 1995), nearly $75 \%$ with a stable occupation, and $78.5 \%$ with an annual salary over RMB 60,000 (Table 10). The research object in study 3 was the environmental friendly car and participants are part of the demographic group most likely to purchase cars in China, thus representative.

ANOVA analysis showed that ecological product preference was not affected by demographic indicators at the 0.01 level, including gender $(p=0.737)$, date of birth $(p=0.083)$, annual salary $(p=0.173)$, education $(p=0.436)$ and profession $(p=0.463)$.

\section{Analysis and results}

\section{Manipulation checks}

The manipulation of materials was measured on two 7-point scales and stated, "DV1: According to the material described above, which car do you think better reflects social status?" and "DV2: According to the material described above, which car do you think releases less pollution to the environment?", followed by endpoints "car A/car B shows social status more" and "car A/car B releases less pollution" respectively. The results of a $T$

Table 10 Study 3: sample descriptive statistics

\begin{tabular}{|c|c|c|c|c|c|}
\hline Gender & Amount & Percentage & Education & Amount & Percentage \\
\hline Male & 129 & $54.7 \%$ & Junior College & 1 & $0.4 \%$ \\
\hline Female & 107 & $45.3 \%$ & Undergraduate & 152 & $64.4 \%$ \\
\hline Date of Birth & Amount & Percentage & Postgraduate and above & 83 & $35.2 \%$ \\
\hline $1961-1973$ & 17 & $7.2 \%$ & Profession & Amount & Percentage \\
\hline 1974-1984 & 113 & $47.9 \%$ & Full-time Students & 52 & $22 \%$ \\
\hline $1985-1995$ & 103 & $43.6 \%$ & Government and Institution Personnel & 14 & $5.9 \%$ \\
\hline After and within 1996 & 3 & $1.3 \%$ & State Enterprise Personnel & 58 & $24.6 \%$ \\
\hline Annual Salary & Amount & Percentage & Foreign Enterprise Personnel & 45 & $19.1 \%$ \\
\hline Below 50,000 & 53 & $22.5 \%$ & Private Enterprise Personnel & 53 & $22.5 \%$ \\
\hline $50,001-100,000$ & 25 & $10.6 \%$ & \multirow{2}{*}{$\begin{array}{l}\text { Self-employed Entrepreneurs } \\
\text { and Freelance }\end{array}$} & \multirow[t]{2}{*}{8} & \multirow[t]{2}{*}{$3.4 \%$} \\
\hline $100,001-300,000$ & 118 & $50 \%$ & & & \\
\hline $300,001-500,000$ & 29 & $12.3 \%$ & Unemployed and others & 6 & $2.5 \%$ \\
\hline Over 500,001 & 11 & $4.7 \%$ & & & \\
\hline
\end{tabular}


test indicate that manipulation is successful. As expected, car A reflected social status more $(\mathrm{M}=2.25<4, p<0.01)$ and car $\mathrm{B}$ was considered less polluting $(\mathrm{M}=6.50>4, p<0.01)$.

\section{Main effect}

First, on the basis of study 2, study 3 took the four generalized indicators of face as grouping variables, in order to inquire into ecological product preference impacted by morality-oriented face (LIAN) and social-oriented face (MIAN). LIAN represents the respect received from the group because of one's morality and MIAN represents social status received from society based on one's success and identity. Therefore, among the 4 dimensions, morality-oriented face from personal inner standards belongs to LIAN and ability-oriented face, status-oriented face and social relationship-oriented face, relevant to one's success and identity, belong to MIAN, which follows the division in Shi et al.'s (2012) work. The first indicator, morality-oriented face is worded, "When my conduct is questioned by others, I feel I have no face". Ability-oriented face, statusoriented face and social relationship-oriented face, are expressed as: "When I am not as capable as others, I feel I have no face", "When I do not have the same social status as others, I feel I have no face" and "When I am embarrassed in social interactions with others, I feel I have no face". The latter three also constitute general social-oriented face.

Next, we divided participants into two groups according to the scores. Group 1 consisted of 97 participants who had a higher score in social-oriented face (versus morality-oriented face), coded as "0". Group 2 included 128 members scoring higher in morality-oriented face oppositely (versus social-oriented face), coded as "1". The remaining 11 participants had equivalent scores in both dimensions. To balance the samples, we attributed these 11 to group 1 , which resulted in 108 samples in group 1 and 128 in group 2.

Besides, using ANOVA, we analyzed scores in ecological product preference (Tables 11 and 12). The mean of the dependent variable of group 1 is 2.74 , while group 2 is 5.52, with significance $(\mathrm{F}=150.622, \mathrm{p}<0.01)$. H1a and $\mathrm{H} 1 \mathrm{~b}$ are therefore supported. Compared to social-oriented face (MIAN), consumers with stronger morality-oriented face (LIAN) prefer ecological products. In contrast, the ones with stronger social-oriented face (MIAN) have more interest in luxury goods.

\section{Conclusion and Discussion}

\section{Conclusion}

This paper innovatively explores both the advantages and disadvantages embedded in the reflective model (RM) and formative model (FM) in constructing face, and furthermore, analyzes the effect on ecological product preference of various dimensions of Chinese face. Initially study 1 finds through empirical study that the RM of face has a better reliability. Then, based on an existing FM of face (Shi et al. 2012), study 2 contrasts these two

Table 11 Mean statistic in study 3

\begin{tabular}{lllcccc}
\hline & $N$ & Means & Standard deviation & Standard error & \multicolumn{2}{c}{ 95\% Confidence interval } \\
\cline { 6 - 7 } & & & & & Lower limit & Upper limit \\
\hline Group 1 & 108 & 2.74 & 1.816 & .175 & 2.39 & 3.09 \\
Group 2 & 128 & 5.52 & 1.655 & .146 & 5.23 & 5.81 \\
Total & 236 & 4.25 & 2.214 & .144 & 3.96 & 4.53 \\
\hline
\end{tabular}


Table 12 ANOVA analysis in study 3

\begin{tabular}{lcllll}
\hline & Sum of squares & Degree of freedom & Mean square & F & Significance \\
\hline Between groups & 451.036 & 1 & 451.036 & 150.622 & .000 \\
Within groups & 700.709 & 234 & 2.994 & & \\
Total & 1151.746 & 235 & & & \\
\hline
\end{tabular}

measurement models with regards to their stability and interpretation of face. Finally, according to the results from study 2, four generalized indicators of four dimensions of face were analyzed as grouping variables for study 3 , so as to test whether different dimensions have differentiated effects on consumers' tendency to purchase ecological products.

Conclusions are as follows: 1) In study 1, the RM of face is verified as having high reliability, and is made up of four factors, namely, morality-oriented face, ability-oriented face, status-oriented face and social relationship-oriented face. 2) We conclude from study 2, RM has greater stability; however, FM is better at interpreting the concept of face. As well, the incremental four generalized indicators of the four dimensions show positive significance with the overall concept of face, along with explained variance $\mathrm{R}^{2}$ at $34.6 \%$. 3) Study 3 deepens study 2 and shows that the separated dimensions of face exert various impacts on consumer ecological product preference. Consumers who have stronger morality-oriented face (LIAN) rather than social-oriented face (MIAN) are more likely to purchase ecological products.

\section{Contribution}

This article makes both theoretical and practical contributions.

In terms of theoretical contributions, first, this paper explores the differences between measurement models of face and their influence, diminishing the confusion about choosing a model to measure face. As a vital component of eastern traditional culture, with both situational characteristics and general characteristics, face is extremely difficult to measure. In some cases, scholars emphasize situational indicators (i.e. causal indicators) to increase accuracy of measurement (Bao and Zhao 2009; Shi et al. 2012). Nevertheless, most use general indicators (i.e. effect indicators) to increase stability (e.g. Zhang 2012; Chan et al. 2009). This is why there simultaneously exists FM of face and RM of face. Choosing the right measurement model is essential for a thorough understanding of a construct. It influences the corresponding empirical study and usage of a structural equation model. Moreover, specifying measurement models contributes to promoting Chinese scholars' empirical studies. Most scholars are keen to argue about causal variables of face as a whole concept, such as the effect of face on the consumption of luxury goods and exclusive goods. Yet most study put the dimensions of face and measurement models aside. Because every researcher has his or her own definition of face, lacking consideration of measurement models, they unintentionally adopt RM, a classic analysis paradigm. Addressing this gap in marketing research, this paper offers a new point of view to examine the detailed dimensions of face and its measurement, as well as develop a better understanding of the connotations of face. Also, this paper provides out-of-the-box thinking for subsequent scholars in exploring and selecting measurement models, with more scientific evidence to explain the mechanisms of face. 
In addition, we further test the difference between LIAN and MIAN and their causal effects on consumer behavior. In Chinese traditional culture, consumption is not only a personal activity, but also a tool to gratify upper-class social needs. Products undoubtedly have instrumental functions, and yet people purchase them because of what they mean, too. Solomon (1983) argued that product purchases are relevant to social status, for people normally judge others by the products they own. Face consists of two dimensions, LIAN and MIAN. The former refers to image and reputation recognized by others gained because of obeying moral norms, and coming from inner morality and self-constrain. However, the latter refers to external personal success and social status, as recognized by the social group. Even though it is universally believed that face is a multidimensional construct, the majority of studies takes face as a whole concept to analyze its relationship to luxury goods consumption, gifts consumption, human consumption and conspicuous consumption. Little research concentrates on the effect of different dimensions of face on consumer behavior, let alone variant effects on ecological product consumption. Through reviewing the relevant literature and empirical studies, this paper explores the difference between LIAN and MIAN, theoretically and practically. As well, these differences directly contribute to differences in ecological product consuming behavior. As stressed again, compared to social-oriented face, consumers with morality-oriented face are more inclined to consume ecological products.

The practical contribution to marketing is distinct, too. Currently, "leading", "dignity", "success" and other words representing "elite" are frequently used in advertising for cars, emphasizing identity or social status. Based on our study, strong morality-oriented face contributes to a predilection for ecological products. Therefore, existing advertisements are probably not appealing to this kind of customers. Especially, present morality is declining so fast in real life that people are afraid to take social moral responsibility (e.g. helping the elderly when they fall down). Hence, there is a good chance that consumers with psychological dissonance and deep moral-self threatened feelings (Carrington et al. 2010), may be interested in other prosocial behavior (e.g. "tiny donation" through popular apps such as Wechat, purchasing low-emission cars). For the promotion of ecological cars, on the one hand, enterprises can take full advantage of consumers' need for LIAN. In advertising campaigns, instead of advocating for social identity, marketers can use terms such as "moral", "decent", "virtuous" to portray a social moral model figure owning an ecological car. On the other hand, companies can stress products' social attributes and moral attributes in the context of an immoral scenario to enhance consumers' social-oriented face needs. Products with outstanding social attributes and moral attributes may be favored by consumers to counteract feelings of unrest and anxiety originating from immoral behavior. So, to prime their ecological product preferences, companies should emphasize that eco-cars can embody social responsibility and generate respect from others.

\section{Limitation}

This paper presents a discussion on two measurement models (RM and FM) and fills the gap underlying the existing research, diminishing confusion about choosing measurement models and offering more scientific proof for the mechanisms of face. Especially, it has implications for policy-makers for Chinese ecological development that we should distinguish the different effects of various dimensions of face on consumer ecological product preference. Limitations, however, remain unavoidable. 
1. Discussion about FM and RM of face remains at an introductory level. Data was analyzed with Smart-PLS only once; however, it needs further investigation into the stability of the overall fit and model. As well, due to time considerations, we re-explored only RM while a more rigorous result would require the re-exploration of FM as well.

2. Scholars claim that people tend to choose moral products mainly via three paths: 1) balance theory with regards to moral or ecological attributes or the halo effect; 2) impression management which cares for others' evaluation and approval of their character; 3) self-responsibility by which individuals hope to maintain their inner moral standards and avoid feelings of guilt. For the first path, companies can appropriately prompt consumer inclination to moral or ecological products, by highlighting the advantages of the other attributes or halo effect. Even though morality-oriented face affects the interest in ecological products through the second and third pathways, the paper did not discuss these mechanisms.

3. Environmentally-friendly vehicles are selected as the object of study. Nonetheless cars belong to consumer goods which are consumed in public. Scholars believe that the second path produces its effect only in public (Griskevicius et al. 2010). Car-buying behavior is one of the most visible consumer actions, which is one of the reasons why we choose environmental friendly cars. Overall, there is a chance that the third path, self-responsibility, is not as affected by whether purchases are more or less visible to other people. In other words, consumers may be more interested in private ecological products (such as energy-saving air-conditioning) in order to meet internal ethical standards. However, we did not address this issue in this paper.

\section{Acknowledgements}

This work is supported by the National Science Foundation of China (No. 71572205) and the Major Research Plan of the Fundamental Research Funds for the Central Universities (16wkjc14). Also, On behalf of our research team, I would like to express our sincere thanks to the two peer reviewers and editors for their critical comments and constructive suggestions.

\section{Authors' contributions}

All authors read and approved the final manuscript.

Competing interests

The authors declare that they have no competing interests.

\section{Publisher's Note}

Springer Nature remains neutral with regard to jurisdictional claims in published maps and institutional affiliations.

Received: 18 September 2016 Accepted: 3 February 2017

Published online: 21 June 2017

\section{References}

Anderson, J. C., \& Gerbing, D. W. (1988). Structural equation modeling in practice: A review and recommended two-step approach. Psychological Bulletin, 103(3), 411.

Bao, G., \& Zhao, Z. (2009). Conceptual structure and measurement of face need: An exploratory research. Journal of Zhejiang University (Humanities and Social Sciences), 39(2), 82-90.

Baxter, R. (2009). Reflective and formative metrics of relationship value: A commentary essay. Journal of Business Research, 62(12), 1370-1377.

Bearden, W. O., \& Etzel, M. J. (1982). Reference group influence on product and brand purchase decisions. Journal of Consumer Research, 9(2), 183-194.

Belk, R. W. (1988). Possessions and the extended self. Journal of Consumer Research, 15(2), 139-168.

Bénabou, R., \& Tirole, J. (2006). Incentives and prosocial behavior. The American Economic Review, 96(5), 1652-1678.

Berger, J., \& Heath, C. (2007). Where consumers diverge from others: Identity-signaling and product domains. Journal of Consumer Research, 34(2), 121-134

Blalock, H. M. (1964). Causal inferences in nonexperimental research. Chapel Hill: University of North Carolina Press.

Bollen, K. A. (1989). Structural equations with latent variables. New York: Wiley.

Bollen, K., \& Lennox, R. (1991). Conventional wisdom on measurement: A structural equation perspective. Psychological Bulletin, 110(2), 305-314. 
Carrington, M. J., Neville, B. A., \& Whitwell, G. J. (2010). Why ethical consumers don't walk their talk: Towards a framework for understanding the gap between the ethical purchase intentions and actual buying behaviour of ethically minded consumers. Journal of Business Ethics, 97(1), 139-158.

Chan, H., Wan, L. C., \& Sin, L. Y. M. (2009). The contrasting effects of culture on consumer tolerance: Interpersonal face and impersonal fate. Journal of Consumer Research, 36(2), 292-304.

Chan, C., Berger, J., \& Van Boven, L. (2012). Identifiable but not identical: Combining social identity and uniqueness motives in choice. Journal of Consumer Research, 39(3), 561-573.

Chen, Z. (1982). Theoretical analysis and empirical study in face psychology. Beijing: Social Science Academic Press.

Chin, W. W. (1998). Issues and opinion on structural equation modeling. MIS Quarterly, 22(1), VII-XVI.

Chou, M. L. 1996. Protective and acquisitive face orientation: A person by situation approach to face dynamic in social interaction. PhD Dissertation, University of Hong Kong.

Coltman, T., Devinney, T. M., Midgley, D. F., \& Venaik, S. (2008). Formative versus reflective measurement models: Two applications of formative measurement. Journal of Business Research, 61(12), 1250-1262.

Connolly, J., \& Prothero, A. (2003). Sustainable consumption: Consumption, consumers and the commodity discourse. Consumption, Markets and Culture, 6(4), 275-291.

Delmas, M. A., \& Lessem, N. (2014). Saving power to conserve your reputation? The effectiveness of private versus public information. Journal of Environmental Economics and Management, 67, 353-370.

Diamantopoulos, A. (2005). The C-OAR-SE procedure for scale development in marketing: A comment. International Journal of Research in Marketing, 22(1), 1-9.

Diamantopoulos, A. (2006). The error term in formative measurement models: Interpretation and modeling implications. Journal of Modeling in Management, 1(1), 7.

Diamantopoulos, A., \& Winklhofer, H. M. (2001). Index construction with formative indicators: An alternative to scale development. Journal of Marketing Research, 38(2), 269-277.

Diamantopoulos, A., Riefler, P., \& Roth, K. P. (2008). Advancing formative measurement models. Journal of Business Research, 61(12), 1203-1218.

Fornell, C., \& Bookstein, F. L. (1982). Two structural equation models: LISREL and PLS applied to consumer exit-voice theory. Journal of Marketing Research, 19(4), 440-452.

Goffman, E. (1967). Interaction ritual: Essays on face-to-face behavior. New York: Garden City.

Griskevicius, V., Tybur, J. M., \& Van den Bergh, B. (2010). Going green to be seen: Status, reputation, and conspicuous conservation. Journal of Personality and Social Psychology, 98(3), 392-404.

Gudergan, S. P., Ringle, C. M., Wende, S., \& Will, A. (2008). Confirmatory tetrad analysis in PLS path modeling. Journal of Business Research, 61(12), 1238-1249.

Ho, D. Y. (1976). On the concept of face. American Journal of Sociology, 81(4), 867-884.

Hu, H. C. (1944). The Chinese concepts of 'face'. American Anthropologist, 46(1), 45-64.

Hwang, A., Soon, A., \& Francesco, A. M. (2002). The silent Chinese: The influence of face and kiasuism on student feedback-seeking behaviors. Journal of Management Education, 26(1), 70.

Jap, W. (2010). Confucius face culture on Chinese consumer consumption values toward global brands. The Journal of International Management Studies, 5(1), 183-192.

Jarvis, C. B., Mackenzie, S. B., Podsakoff, P. M., Mick, D. G., \& Bearden, W. O. (2003). A critical review of construct indicators and measurement model misspecification in marketing and consumer research. Journal of Consumer Research, 30(2), 199-218.

King, A. Y., \& Myers, J. T. (1977). Shame as an incomplete conception of Chinese culture: A study of face. Chinese University of Hong Kong. Hong Kong: Social Research Centre.

Li, J. J., \& Su, C. (2007). How face influences consumption. International Journal of Market Research, $49(2), 237-256$

Lin, Y. (1935). My country and my people. New York: Reynal \& Hitchcock.

Mackenzie, S. B., Podsakoff, P. M., \& Jarvis, C. B. (2005). The problem of measurement model misspecification in behavioral and organizational research and some recommended solutions. Journal of Applied Psychology, 90(4), 710-730.

Milinski, M., Semmann, D., \& Krambeck, H. J. (2002). Reputation helps solve the 'tragedy of the commons'. Nature, 415(6870), 424-426.

Peloza, J., White, K., \& Shang, J. (2013). Good and guilt-free: The role of self-accountability in influencing preferences for products with ethical attributes. Journal of Marketing, 77(1), 104-119.

Petter, S., Straub, D., \& Rai, A. (2007). Specifying formative constructs in information systems research. MIS Quarterly, 31(4), $623-656$.

Rossiter, J. R. (2002). The C-OAR-SE procedure for scale development in marketing. International Journal of Research in Marketing, 19(4), 305-335.

Shi, Z., Fan, L., \& Wen, L. (2011). A study on the effect of face perception on the implicit and explicit brand attitude toward country of origin. Journal of Marketing Science, 7(3), 25-41.

Shi, Z., Ichiro, F., \& Jin, C. (2011). Cognitive discrepancy in Chinese 'face': Mian and lian, and their impact on cognition of country-of-origin image. Frontiers of Business Research in China, 5(2), 163-178.

Shi, Z., Fan, L., \& Ye, J. (2012). An empirical study on Chinese face and its effect on consumer's attitude toward advertising of luxury. Nankai Business Review, 1, 151-160.

Shi, Z., Wu, L., \& Kuang, Z. (2014). How face consciousness reverse pro-self behavior? A study on sustainable consumption from the perspective of social value orientation. Journal of Marketing Science, 10(2), 59-81.

Solomon, M. R. (1983). The role of products as social stimuli: A symbolic interactionism perspective. Journal of Consumer Research, 10(3), 319-329.

Tse, D. K. (1996). Understanding Chinese people as consumers: Past findings and future propositions (pp. 352-363). New York: Oxford University Press.

Wong, N. Y., \& Ahuvia, A. C. (1998). Personal taste and family face: Luxury consumption in confucian and western societies. Psychology \& Marketing, 15(5), 423-441.

Wong, A. C. Y., \& Zaichkowsky, J. L. (1999). Understanding luxury brands in Hong Kong. European Advances in Consumer Research, 4, 310-316.

Zhai, X. (1995). Model of Chinese people's face consciousness. Beijing: Social Science Academic Press. 
Zhang, X. (2012). Chinese people's face consciousness and conspicuous consumption of luxury goods. Journal of Marketing Science, 8(1), 76-94.

Zhou, M., He, Y., Yang, G., \& Yu, A. (1993). Analyzing the connation of face and its mechanisms in social interaction from cross-cultural perspective. Beijing: Social Science Academic Press.

Zhou, N., Zhuang, G., \& Yip, L. S. (2007). Perceptual difference of dependence and its impact on conflict in marketing channels in China: An empirical study with two-sided data. Industrial Marketing Management, 36(3), 309-321.

Zhu, R. (1987). Social interaction of Chinese people: On the issue of face. In Collected into Chinese Social Psychological Review: 2005(2):79-106. Beijing: Social Science Academic Press.

\section{Submit your manuscript to a SpringerOpen ${ }^{\circ}$ journal and benefit from:}

- Convenient online submission

- Rigorous peer review

- Open access: articles freely available online

- High visibility within the field

- Retaining the copyright to your article

Submit your next manuscript at $\gg$ springeropen.com 